\title{
High-speed RZ-DPSK photonic integrated transmitter for space optical communications (Erratum)
}

Joseph Fridlander, Victoria Rosborough, Fengqiao Sang, Sergio Pinna, Steven Estrella, et al.

Joseph Fridlander, Victoria Rosborough, Fengqiao Sang, Sergio Pinna, Steven Estrella, Leif Johansson, Jonathan Klamkin, "High-speed RZ-DPSK photonic integrated transmitter for space optical communications (Erratum)," Proc. SPIE 11133, Laser Communication and Propagation through the Atmosphere and Oceans VIII, 1113316 (18 October 2019); doi:

$10.1117 / 12.2558903$

SPIE Event: SPIE Optical Engineering + Applications, 2019, San Diego, California, United States 


\section{High-Speed RZ-DPSK Photonic Integrated Transmitter for Space Optical Communications}

Joseph Fridlandera, Victoria Rosborougha, Fengqiao Sanga, Sergio Pinnaa, Steven Estrellaa,b, Leif Johanssonb, Jonathan Klamkina aElectrical and Computer Engineering, University of California, Santa Barbara, CA 93106, USA; bFreedom Photonics, 41 Aero Camino, Santa Barbara, CA 93117, USA;

Proceedings Volume 11133, Laser Communication and Propagation through the Atmosphere and Oceans VIII; 1113309 (2019) https://doi.org/10.1117/12.2528213

Event: SPIE Optical Engineering + Applications, 2019, San Diego, California, United States

Online Publication Date: 6 September 2019

Erratum Published: 18 October 2019

A revision of this manuscript was published on 18 October 2019. Details of the revision are provided in the text that accompanies this Erratum. The original paper has been updated.

Figure 6 - a correction was made to the duplicate plot 